A Deleuzian Reimagining of Susanne Langer's Philosophy:

Becoming-Feeling in Music Education

Lauren Kapalka Richerme

Indiana University Jacobs School of Music

\begin{abstract}
Author Note
Lauren Kapalka Richerme is assistant professor of music education at the Indiana University Jacobs School of Music. Her research interests include philosophy and education policy.

Correspondence concerning this article should be addressed to Lauren Kapalka Richerme, Music Education Department, Indiana University Jacobs School of Music, 1201 E 3rd St., Bloomington, IN 47405. Contact: 812-855-4430 (office), 484-883-3032 (cell), lkricher@indiana.edu
\end{abstract}

Word count: 7030 


\begin{abstract}
While Langer's assertions about feeling and art have had a marked impact on music educators’ thinking and action, they have also earned substantial critique. The purpose of this philosophical inquiry is to examine Langer's and Deleuze's writings about the ontology of art and to posit a new concept, “becoming feeling,” inspired by the meeting of their philosophies. Deleuze’s assertions about forces, intensities, and becomings avoid the pitfalls of Langer's statements about music’s symbolic nature, but his focus on "nonhuman becomings" has the potential to neglect the emotional aspects of humanity that Langer finds central to musical experiences. I offer that artistic experiences foster "becoming-feeling," which involves sensing the world as though one were specific, continually-changing feelings. Examples of how musically educative experiences centered on "becoming-feeling” might lead to more refined and ordered understandings as well as to more complex and confused ones are offered.
\end{abstract}

Keywords: Langer, Deleuze, feeling, becoming, music education 


\section{A Deleuzian Reimagining of Susanne Langer's Philosophy: Becoming-Feeling in Music Education}

Every generation of music educators grapples with the creation, maintenance, and ultimate transformation of philosophical positions meaningful for their time and place. While researchers ranging from neuroscientists to sociologists have examined the relationship between feelings and musical experiences, philosophers provide a unique perspective on the nature of such interactions. For over four decades, Susanne Langer's assertions about feeling and art have had a marked impact on music educators' thinking and action, most notably through the writings of Bennett Reimer (1970, 1989, 2003). Yet, music educators such as Wayne Bowman (1998) and David Elliott and Marissa Silverman (2015) have leveled substantial critiques at Langer's philosophy. Since empirical evidence supports the centrality of feelings to musical experiences (e.g., Campbell, Connell, and Beegle 2007; DeNora 1999), music educators might benefit from a reimagining of Langer's work that maintains her emphasis on feeling while remedying her demonstrable philosophical drawbacks. ${ }^{1}$ Although French poststructuralist philosopher Gilles Deleuze's arguments regarding the role of sensations, affects, and percepts in artistic experiences also have notable limits, his work avoids many of the Langer's pitfalls.

Breaking from longstanding Western philosophical practices, Deleuze and co-author Féliz Guattari (1994) propose that philosophizing involves the invention or fabrication of new concepts. Rather than transcendent entities, these concepts evolve and "must relate to our problems, our history, and, above all, to our becomings” (27). As Todd May (2005) summarizes, Deleuze creates "concepts of difference" in order to engage readers in considering "living at different levels” (24). The purpose of this philosophical inquiry is to examine Langer's and Deleuze's writings about the ontology of art. $^{2}$ Subsequently, in agreement with Deleuze and 
Guattari’s philosophical practices, I posit the formulation of a new concept, "becoming-feeling,” inspired by the meeting of their philosophies.

\section{What is Art?}

Like many philosophers, Langer and Deleuze afford the arts a unique place among human activity, differentiating them from both philosophical and scientific practices. ${ }^{3}$ Despite this overarching agreement, Langer's and Deleuze's positions on art's nature and content diverge markedly. Distinguishing between discursive symbolism and presentational symbolism, Langer (1951) argues that in discursive symbolism, including everyday speech, meaning occurs as one makes sense of each term individually and combines them to make a whole. Conversely, in the presentational symbolism found in works of art, one makes meaning by engaging with the whole. An artistic symbol “involves all the relationships of its elements to one another” (Langer 1953, 51, emphasis hers). For example, while adding the meaning of each word in isolation enables a basic understanding of a sentence, individuals make little meaning out of a single musical pitch or chord without hearing its relations with the rest of a phrase.

Additionally, discursive symbols reference ideas beyond themselves; a sentence about a child playing with a red ball indicates specific material engagements outside of the words in the sentence. In contrast, Langer $(1953,1957)$ argues that artworks negotiate insight rather than reference. She explains, "A work of art is an expressive form, and therefore a symbol, but not a symbol which points beyond itself so that one's thought passes on to the concept symbolized" $(1957,67)$. Artistic symbols convey ideas to those who engage with them without moving individuals' attention away from the symbol itself. ${ }^{4}$

If artworks are symbolic, what exactly do they symbolize? While Langer (1953) repeatedly answers that artworks express "human feeling” (e.g., 28, 40, 51), she also offers 
variations, including “emotion” (1953, 374), “inner life” (1953, 28; 1957, 7), "the nature of human feeling” (1957, 7), and “ideas of feeling” $(1953,59)$. Bowman (1998) summarizes that while in Langer's earlier work "feeling was synonymous with emotion," she later expanded her definition to include forms such as "growth and attenuation" and "conflict and resolution" (214). These feelings are "in" the artwork, "not through it mediately" (Langer 1957, 34). Langer (1957) also qualifies that artworks do not necessarily present the artist's feeling at the time he or she created the artwork or the performer's feeling while engaging with an artwork, but rather feelings the artist "knows" (91).

Building on this ontology of art, Langer (1957) asserts that a work of art is "good" insofar as it objectively presents the character of inner life for "contemplation, logical intuition, recognition, understanding” (133). Art's value depends on the extent to which it clearly reveals the idea of feelings in ways that expand participants' understandings of those feelings. An artwork that expresses feelings ambiguously or that does not offer new insights into the character of inner life therefore possesses less value than one that precisely communicates the intricacy of specific ideas of feelings. ${ }^{5}$

In contrast, Deleuze conceives of art as "forces" and "becomings.” Writing with coauthor Guattari, Deleuze (1987) explains that in art, "The essential thing is no longer forms and matters, or themes, but forces, densities, intensities” (343). Instead of conceiving of artworks as stagnant entities worthy of sustained dispassionate contemplation, Deleuze and Guattari emphasize their variability and evolving interrelationships with chaotic local contexts. It follows that artists seek ruptures and ongoing transformation rather than transcendence. Asserting that the artist is “a seer, a becomer,” Deleuze and Guattari (1994) offer the example of van Gogh 
being “caught in a becoming-sunflower” (170-171). Contextualizing such statements within Deleuze’s various explanations of “becoming” offers further clarification.

While Deleuze initially used the term "becoming” to designate any sort of instability or change, in his later writings, he applied "becoming” almost exclusively to specific types of becomings, including becoming-woman, becoming-animal, and becoming-imperceptible (May 2003). These specific becomings involve movement away from dominant norms. Deleuze and Guattari (1987) argue, “There is no becoming-majoritarian; majority is never becoming” (106). According to Deleuze (1995), the difference between “majorities” and “minorities,” is not size but consistency; he explains, "What defines the majority is a model you have to conform to: the average European adult male city-dweller, for example. . . . A minority, on the other hand, has no model, it's a becoming, a process" (173). In other words, Deleuze and Guattari view “majorities” as homogenous, constant entities that resemble known ideals and minorities as diverse, continually-changing subjectivities that defy clear classifications. While man, human, and perceptible serve as normative models, woman, animal, and imperceptible remain secondary and ambiguous. Becoming, then, is the process through which one embraces variability and motion, turning away from history in order to "create something new” (Deleuze and Guattari 1994, 96).

These explanations address becoming in the abstract, but what about the experience of becoming? Deleuze and Guattari (1987) directly contrast becoming with imitation, noting that becoming-animal, in this case a dog, occurs when an organism enters "into composition with something else in such a way that the particles emitted from the aggregate thus composed will be canine as a function of the relation of movement and rest” (274). In other words, becominganimal involves changing events that blur divides between human and animal; the one becoming 
is neither other to the dog nor like the dog but a confluence of human-dog intensities. Claire Colebrook (2002) summarizes:

Becoming-animal is not, then, attaining the state of what the animal means (the supposed strength or innocence of animals); nor is it becoming what the animal is. It is not behaving like an animal. Becoming-animal is a feel for the animal's movements, perceptions and becomings: imagine seeing the world as if one were a dog, a beetle or a mole. (136, emphasis hers)

For example, by “becoming-sunflower," van Gogh does not mimic or change into the form of a sunflower. Rather, by sensing the world as though he were a sunflower, he does what Elizabeth Grosz (1995) explains as entering into an “arrangement” or “relation” with the sunflower; he forms "part of a machine, a component in a series of flows and breaks, of varying speeds and intensities” (184). This motion, however, is not part of a broad developmental trajectory, but instead "something momentary, provisional, something inherently unstable and changing” (Grosz 1995, 184). Through such experiences, van Gogh temporarily moves away from a majoritarian ways of seeing and knowing in order to imagine and engage with the world anew.

Those creating art are not the only ones transformed by artistic encounters; Deleuze and Guattari (1994) also reference the becomings of those engaging with existing artworks, stating that artists “make us become with them” (175). Going further, they posit the evolutionary nature of artworks themselves, writing, "Musical expression is inseparable from a becoming-woman, a becoming-child, a becoming-animal that constitute its content” $(1987,299)$. The process of "becoming” constitutes the ontology of art as well as the experience of art for both artistic creators and participants. In short, Deleuze conceives of artworks as transformative forces that 
enable those who create and engage with them to break from established patterns and stagnant modes of being.

Since Deleuze asserts an ontology of existence comprised of forces and becomings, such processes are not unique to artworks and artistic endeavors. In order to distinguish artworks and artistic becomings from other activity, Deleuze posits the existence of sensations, affects, and percepts. For Deleuze, sensation serves a dual function: the tool that artists use to create and the product of their creation. He and Guattari (1994) state, "We paint, sculpt, compose, and write with sensations. We paint, sculpt, compose, and write sensations” (166). Ronald Bogue (2003) elaborates that rather than being projected onto surfaces, sensation "rises up into a metamorphic plane of forces. In painting, the paint itself - its thickness, saturation, texture, etc. - articulates forces; in music, variegated timbres, microintervals, and fluctuating rhythms make up a malleable sonic force-matter” (169). Stated differently, Grosz (2008) explains that the arts "extract something imperceptible form the cosmos and dress it in the sensible materials that the cosmos provides in order to create sensation, not a sensation of something, but pure intensity” (22). Art is not colors trapped in a canvas or notes suspended in time but forces that propagate through artistic endeavors and beyond.

Along with sensations, Deleuze and Guattari note the role of what they term "affects” and “percepts” in artistic experiences. Affects and percepts are related to affections and perceptions. Colebrook (2002) explains affections as what happens to us as a result of an event, such as when one's nostrils recoil from the smell of cheese, and perceptions as what one receives, in this case the odor or smell itself (21-2). Affections and perceptions are located in perceivers - one has an affective response of fear or one perceives red - while affects and percepts lack a point of view (Colebrook 2002, xix-xx). Deleuze and Guattari (1994) write, “The aim of art is to wrest the 
percept from perceptions of objects and the states of a perceiving subject, to wrest the affect from affections as the transition from one state to another: to extract a bloc of sensations, a pure being of sensations” (167). In such instances, the affective response of fear and perception of red become an affect of fear and percept of red disconnected from artwork, creator, and perceiver. Sensations, affects, and percepts provide a way of understanding how artworks relate with human feelings while not necessarily evoking particular feelings. Similar to Langer's assertions that artists and audiences need not necessarily directly experience the feelings symbolized in a work of art, Colebrook (2002) uses the following to exemplify Deleuze’s ideas: “Imagine a painting that just is terrifying or depressing; we may not be depressed or terrified when we view it but it presents the 'affect of depression or terror'” (xx).

Once created, sensations, percepts, and affects exist, propagate, and disseminate regardless of whether or not individuals receive them. Deleuze and Guattari (1994) argue, "Sensations, percepts, and affects are beings whose validity lies in themselves and exceeds any lived" (164, emphasis theirs). Noting the mobile nature and mobilizing potential of sensations, Grosz (2008) summarizes that art "emerges when sensation can detach itself and gain an autonomy from its creator and its perceiver" (7). Yet, sensations do not just move passively throughout the world, but rather alter what they encounter in and through their meetings. Sensations are "mobile and mobilizing forces," occupying a liminal space between the "fully objective and measurable” and the subjective or experiential (Grosz 2008, 76). While shared by subject and object, sensation remains irreducible to subject, object, or their relations (Grosz 2008, 8).

Conceiving of artistic endeavors as involving forces has consequences for the embodied aspects of humans' artistic experiences. Grosz (2008) explains, "Sensation is that which is 
transmitted from the force of an event to the nervous system of a living being and from the actions of this being back onto the world itself” (71). In Bogue’s (2003) terms, sensation renders visible "the invisible forces that play through bodies" (125). Through its vibrations and resonance, sensation moves within and beyond humans’ bodies, opening them to new becomings. For Deleuze and Guattari, enabling experiences that extend and transform one’s current imaginings and limits is a key function of art.

It follows that Deleuze and Guattari conceive of artworks as contextual and emphasize the importance of innovation rather than replication. Colebrook (2005) explains, “An artwork would be great not if it fulfilled already existing criteria for what counts as beautiful, but if it took the power for creating beauty - the power to prompt us to bathe in the sensible - and produced new and different ways of confronting sensibility” (181). This newness occurs both within art, when music overturns "the very codes that structure or arborify it" (Deleuze and Guattari 1987, 11-12), as well as beyond it, as when art confronts "a question of freeing life wherever it is imprisoned, or of tempting it into an uncertain combat” (Deleuze and Guattari 1994, 171). Stated differently, Deleuze and Guattari (1987) note the possibilities of art to incite societal rupture, chaos, and multiple paths forward, creating “a people to come” (345). As Grosz (2008) summarizes:

Art is intensely political not in the sense that it is a collective or community activity ... but in the sense that it elaborates the possibilities of new, more, different sensations than those know. Art is where the becomings of the earth couple with the becomings of life to produce intensities and sensations that in themselves summon up a new kind of life. (79) 
Deleuze emphasizes the interplay of artistic sensations and social endeavors, endowing artistic experiences with the task of realizing previously unimagined potentialities of individual and communal life.

Deleuze's ontology of art comprised of difference and motion contrasts Langer's assertions about the symbolic nature of art. If artworks are composed of forces, as Deleuze posits, then they are inherently unstable. Langer (1957) at times hints at the variability of artworks; for example, she articulates the concept of "living form," which she explains as "a form whose permanence is really a pattern of changes" (52). Yet, her maintenance of the word "symbol" and insistence that each artwork "unambiguously" expresses particular ideas of feeling strongly favor a static conception of art that contrasts not only Deleuze's philosophy of art but his entire metaphysics. Colebrook (2002) summarizes that for Deleuze, “Art is not about knowledge, conveying 'meanings' or providing information.... Art may well have meanings or messages but what makes it art is not its content but its affect, the sensible force or style through which it produces content” (24-25, emphasis hers).

At one point, Langer (1957) writes broadly about the potential for the arts both to stabilize and to "advance" culture (72), although she does not explain how or why they might do this. Additionally, Langer (1957) warns, "A society that neglects [art education] gives itself up to formless emotion” (74). While both Langer and Deleuze assert an interrelationship between art and society, Langer suggests teleological advancement while Deleuze posits imaginative societal transformation.

Although Langer's use of the word "feelings" may initially seem compatible with words such as “sensation,” "percept,” and “affect,” Deleuze (1995) directly contrasts affects with feelings, writing, “Affects aren’t feelings, they’re becomings that spill over beyond whoever 
lives through them” (137). Feelings are limited to sentient beings, but affects move freely through all forms of existence. Deleuze and Guattari (1987) do not completely dismiss the idea of human feelings in art, writing, "In the motif and the counterpoint, the sun, joy or sadness, danger, become sonorous, rhythmic, or melodic” (319). While various artworks may at times express feelings such as joy or sadness, Deleuze and Guattari's juxtaposition of such terms and objects such as the "sun" contradicts Langer's assertions about the centrality of human feeling to artistic endeavors.

\section{Limitations}

While music educators may find aspects of Langer's and Deleuze's philosophies fruitful in facilitating alternative understandings and practices, their writings are not without limitations. Bowman (1998) offers a thorough critique of multiple aspects of Langer's philosophy, including two problems of particular relevance to the aforementioned ideas: her ambiguous explanation of what art symbolizes and the faulty premises underlying her assertions about the nature of symbolization. First, Bowman (1998) explains that Langer neglects to define terms such as “feeling” and "forms of feeling” (214). Lars-Olof Ahlberg (1994) summarizes that in Philosophy in a New Key alone, Langer makes the following claims:

(1) Music formulates and represents emotions and moods; (2) Music articulates complexes of feeling; (3) Music presents emotive experience; (4) Music reveals the nature of feelings; (5) Music reflects the morphology of feeling. (74-5)

Ahlberg asserts that these statements are neither the same nor mutually compatible. Given that Langer conceives of music as symbols that communicate unambiguously, this lack of clarity makes understanding the content that music presents difficult, thus undermining a key part of her argument. Additionally, Bowman (1998) states that Langer's later assertion that music can 
convey forms such as conflict and resolution further muddies her arguments and makes the role of feelings in musical experiences less significant.

A second pervasive limit of Langer's writing is her assumption that close resemblance, in this case between music and feeling, demands symbolism. Bowman (1998) writes, "If similarity of pattern were sufficient to establish music as a symbol, we would be obliged to say music symbolizes any number of things it resembles - including many that have little to do with music or symbolization” (217). Philip Alperson (2004) goes further, deeming Langer’s work “underdetermined” because of her unsubstantiated claim that "of all the things with which musical forms might be isomorphic, music must symbolize the life of feeling” (266, italics his). In short, resemblance does not necessary establish symbolism, and close resemblance does not equate with more accurate or significant symbolism.

Langer's distinction between discursive and presentational symbols clouds her already limited argument. Bowman (1998) problematizes Langer’s assertions about presentational symbols' simultaneous intransigence and expressive nature, noting the logical flaw in positing a symbol "whose significance simultaneously does yet does not reach beyond its presentation" (219). Since Langer never resolves the tension between a symbol conveying information yet not pointing to anything beyond itself, she does not convincingly demonstrate that music is symbolic.

Elliott and Silverman (2015) point out two additional drawbacks. They critique Langer for asserting that music presents but does not arouse emotions, feelings, or moods, noting that such a position ignores both neuroscience research and "what most people value most about music making and listening - deep, direct, and immediate experiences of felt emotions” (313). Alperson (2004) makes a similar point, noting that while Langer avoids the problems of talking 
about music as expressing definite emotions, she does so at the expensive of engaging with the fact that "the bulk of critical talk about music does employ the language of particular emotions" (266). Additionally, Elliott and Silverman (2015) argue that Langer posits a false dichotomy between discursive symbols and presentational symbols, explaining that the temporal, emotionally-laden nature of everyday language contradicts Langer’s assertions about its discursive symbolic function.

A fifth potential drawback of Langer's philosophy of art that remains unaddressed in existing literature is the disconnection between the role of art in society and the symbolic value of art. While Langer (1957) warns that societies neglecting art education give themselves over to “formless emotion," the social benefits of educating feeling and the dangers of not educating feeling go unexplained. One can imagine instances in which the artistic endeavors undertaken by uneducated masses have aided in the toppling of oppressive regimes, arguably enabling societal advancement. ${ }^{6}$ The assumption that engaging with "good” artworks - meaning those that unambiguously convey "forms of feeling” - can benefit or "advance” society is would need additional explication in order to be convincing.

Like Langer’s writings about “feelings” and “ideas of feelings,” Deleuze’s explanations of “sensations," "affects,” and “percepts” lack clarity. However, this ambiguity is in part Deleuze’s intent; May (2005) explains that instead of aiming to settle old questions, readers should turn to Deleuze's work in order to become unsettled. Despite the new potentialities for life that confusion may facilitate, Deleuze’s writings are limiting because they do not provide readers a clear way to distinguish art from non-art and artistic experiences from other experiences. 
Although Deleuze and Guattari (1994) posit affects as specific to artistic experiences, they also explain them as "nonhuman becomings" (169). Elsewhere, they specifically call musical expression "inseparable from a becoming-woman, a becoming-child, a becoming-animal that constitute its content” $(1987,299)$. Yet, they imply that other events can also trigger such experiences, writing, "We can be thrown into a becoming by anything at all, by the most unexpected, most insignificant of things” $(1987,292)$. Such statements seem to contradict Deleuze and Guattari's own assertions about the unique nature, function, and value of art and artistic endeavors.

Another potential limit of Deleuze's artistic philosophizing is that his focus on "nonhuman becomings" omits the emotional aspects of the human condition that many philosophers, including Langer, find central to artistic experiences. Contextualizing these “nonhuman becomings” within Deleuze and Guattari’s broader philosophy illuminates the motivation guiding such assertions. Consistent with the challenging of foundations and stagnant distinctions that permeates Deleuze and Guattari’s writings, through their emphasis on "nonhuman becomings," they resist the treatment of human beings as a natural, primary category in a privileged position. Villani (2006) articulates the need for such resistance, asserting that the striving for human perfection that begin in the eighteenth century has led to the development of "a hyper-morality of pure conformity" that aims "at the 'better', or at least the 'correct”" within spheres ranging from politics to economics to philosophy (231). Privileging humanity above other distinctions fosters uniform, immobile orderings of people and ideas, resisting alternative reimaginings of what life might become.

This does not mean that humans do not fit into Deleuze and Guattari's ontology. May (2005) explains: 
There is no reason to privilege the life of the subject above other lives. Nor is there any reason to reject it. It is one perspective on difference, one way of getting a conceptual hold of it. There are others, neither more nor less adequate. Or, rather their adequacy depends on how they contribute to living. The mistake all along was to believe that there was only one, and that it was the human one. (24)

By facilitating “nonhuman becomings," artistic endeavors have the potential to counter hierarchies and forms of standardization that humanism propagates. Grosz (2008) notes, “Affects are the ways in which the human overcomes itself," converting the self into a "being of sensation” - “a work of art” (77). Despite the possibilities of such becomings, I wonder: What is lost when one emphasizes nonhuman becomings while minimizing attention to subjugated aspects of one's humanity, including the feelings and emotions so often relegated through the efficiency-oriented cognitive-centrism permeating contemporary life?

May (2005) interprets focusing on human parts and qualities rather than on individual humans as a form of nonhuman becoming. He explains that the difference in a nonhuman becoming can include "my hand or my relationship with my wife or the way my body navigates through a crowded room” (24). It follows that focusing on feelings or emotions, as opposed to individual human beings, also forwards Deleuze's aim of troubling the conception of "human” as a foundational category. Yet, Deleuze's emphasis on pre-personal sensations, affects, and percepts may encourage readers to neglect the role human qualities such as emotions and feelings can and might play in artistic engagements.

\section{A Proposal for Becoming-Feeling}

While Langer and Deleuze deal primarily with the question "What is art?” I use their writings to explore the question "When is an artistic experience?"7 Contemporary artists have 
purposefully challenged the distinction between art and non-art, famously turning a urinal into visual art (Duchamp’s Fountain) and the sounds permeating “silence” into music (Cage’s 4'33”). Through such action, these artists blur the boundary between art and non-art to such an extent that broad definitions of art necessarily encompass most of existence while narrow ones exclude many contemporary artistic endeavors. Since focusing on “artistic experiences” considers when individuals may deem urinals or "silence” as "art” and when they may not, such inquires provide understandings relevant for engaging with contemporary artistic practices as well as past ones. For Langer, engaging with the question "When is an artistic experience?" involves asking when humans experience the symbolic unambiguous communication of feeling; for Deleuze, it involves considering when affects, percepts, and sensations foster becomings. Deleuze’s assertions about forces, intensities, and becomings avoid the aforementioned pitfalls of Langer's statements about the symbolic nature of artistic endeavors. Through such a conception, Deleuze frees artistic experiences both from having to represent or present and from needing to communicate unambiguously. Yet, Deleuze’s emphasis on pre-personal sensations and affects may be complemented by further attention to the feelingful aspects of artistic experiences that humans often find meaningful. Drawing inspiration from Langer's assertions about the relationship between feeling and art and Deleuze's philosophy, I posit that artistic experiences can involve what I term the concept of "becoming-feeling.”

In alignment with Deleuze’s writings about “becoming,” “becoming-feeling” does not consist in imitating a feeling, transforming into a feeling, or changing into what a feeling means. Instead, "becoming-feeling” occurs when individuals enter into relations with particular feelings, in part perceiving the world as though they were a specific feeling. For example, while Deleuze and Guattari (1994) describe van Gogh as “caught in a becoming-sunflower” (170-171), van 
Gogh may also "become-feeling” as he envisions and paints sunflowers in integration with the motion and changing intensities of certain feelings. An artist paints a sunflower imagined and engaged with through feeling components more closely linked to the category of “joy” differently than one perceived through the general categories of "anxiety” or "sadness.”

Individuals need not create art in order to "become-feeling.” For instance, those viewing one of van Gogh's Sunflowers may find that the painting encourages them to understand aspects of themselves through what one might broadly term "melancholy," or they may perceive their fellow gallery-goers or surrounding space through “sadness.” While observers may initially view the white walls on either side of the painting as neutral, when "becoming-feeling" through engaging with Sunflowers, they may sense the walls as places filled with mobile intensities of emptiness or despair.

Consistent with Langer, I argue that while humans have general terminology to speak about feelings, including words such as “joyful” and “angry,” we ultimately lack a comprehensive vocabulary to describe their complex and evolving nature. For example, the term “joy” does not do justice to the sense of comradery and common humanity in Beethoven’s Symphony No. 9, and the word "anger" does not capture the power and intensity of the Ewe drumming song Agbekor. Additionally, one does not perceive the world through the same feeling intensities broadly called “joy” at the start of Beethoven’s Symphony No. 9 as at the end. As such, “becoming-feeling,” like feelings themselves, is a continually-varying, contextuallybound experience unique to each individual.

Given the limits of an artistic philosophy dependent on "feeling” without a coherent explanation of that term, further clarification is needed. Like Elliott (1995) and Elliott and Silverman (2012, 2015), I distinguish between "emotions” and "feelings” and limit "becoming- 
feeling” to “feelings,” excluding more amorphous ideas such as "inner life” and "growth.” Neuroscientist Antonio Damasio (1999) differentiates emotions from feelings, asserting that emotions are automatic, unconscious physical responses to external stimuli, and feelings are the cognitive awareness of these embodied-emotional reactions. In other words, as emotions integrate with cognition, they transform into what neuroscientists term "feelings.” This cognitive process occurs inseparably from subconscious thoughts, memories, and images linked to particular emotions. While humans can experience emotions in the form of a fight or flight response without conscious thought, the vast majority of emotions become feelings almost instantaneously (Damasio 1999).

Artistic experiences may induce emotions absent conscious intervention, but such events occur no differently than other fight or flight responses. For instance, if individuals become startled by a large red canvas or loud cymbal crash, they experience physiological changes. If such individuals’ bodies initially respond to the stimuli without conscious cognitive intervention, they will experience emotional reactions identical to those triggered by a flash of lightening or clap of thunder. These embodied-emotional reactions often become feelings almost instantaneously as the mind identifies one’s experience as "fear." Even if one does not expressly think "I am afraid," as her cognition integrates with these physiological emotional responses, the emotion of fear quickly becomes a feeling of fear (Damasio 1999).

"Becoming-feeling” occurs differently than having feelings. For instance, partners engaged in an argument may experience feelings of anger or frustration because they are angry they are having an embodied-emotional experience of anger - not necessarily because they sense the world in integration with feeling intensities broadly categorized as “anger." In contrast, those listening to the first movement of Beethoven’s Symphony No. 5 may discover angry striving 
vibrations within themselves even if they do not have the embodied-emotional reactions associated with feeling angry. While being angry demands certain physiological changes, "becoming-angry” is a way of sensing the world that invokes varying, continually-changing cognitive-embodied experiences.

Artistic experiences may involve both experiencing feelings and engaging with the world through varying human-feeling flows and relations. Individuals hearing certain Afro-Cuban music may, for example, experience the cognitive-embodied-emotional responses associated with the category of feelings called "happiness" while simultaneously experiencing themselves and the world as if they were specific feelings of happiness. In moments involving both feeling happy and "becoming-happy," individuals cannot necessarily distinguish the boundaries of each. I acknowledge that this distinction between feeling and "becoming-feeling" is in need of additional refinement; as such, I posit it not as a strict dichotomy but as a messy starting place for future investigation. Before suggesting possible implications of such thinking for music education, I offer one additional idea also in need of further development.

I tentatively posit that "becoming-feeling” may distinguish artistic experiences from other human endeavors. Various events can induce changes in participants’ perceptions; for instance, those leaving a winning baseball game may feel a sense of joyful community when exiting the stadium. Yet, it is my preliminary contention that such alterations result more from shared feelings - communal elation or disappointment - than from the altered sense of self and the world possible through "becoming-feeling.” As potential support for this difference, take the contrast of journeying home after a sports event verses after a musical one. While sports fans may feel certain emotions following a game, they rarely perceive facets of the roadway or their neighborhoods anew. Conversely, those leaving musical experiences may make observations 
consistent with their "becoming-feelings;” individuals returning from a performance of Indian classical music may take note of the peaceful swaying of trees or meditative patterns on building facades, while those leaving a playing of George Crumb’s Black Angels may find themselves newly aware of an eeriness in the glow of street lamps or an unsettling array of trash in a dark alley. Extending these provisional assertions, I ask: "What might a conception of artistic experiences as involving 'becoming-feeling' mean for music education?”

\section{Becoming-Feeling in Music Education}

Through standardized goals and assessments that favor knowledge, thought processes, and skills without acknowledgement of humans' feelings, contemporary education policy and practice tends to foreground a cognitive-centric worldview. Likewise, the authors of key music education policy documents have largely omitted the discourse of feeling. ${ }^{8}$ At the broadest level, if "becoming-feeling” may be a process unique to artistic engagements, then music educators at all levels might consider the role that such discourse could play in their standards, curricula, advocacy resources, and other documents as well as to what extent they emphasize feelings when teaching.

Despite the difference between having feelings and "becoming-feeling," if teachers and students do not acknowledge the former, they may find it difficult even to begin broaching the more abstract latter. As such, teachers might ask: Are statements about feelings part of every teaching and learning endeavor? Do students feel safe talking about and experimenting with the relationship between music making and feeling? Do I share my own experiences of becomingfeeling with students? When and how might I and others discuss the role of feelings in music making with parents, policymakers, and other constituents? 
More specifically, combining Langer’s and Deleuze’s writings suggests possible educative practices related to “becoming-feeling” that utilize and augment Reimer's application of Langer to music education. Teachers and students will inevitably become-feeling differently over the course of their musical experiences. For example, students improvising over a 12-bar blues for the first time may have minimal if any experience of becoming-feeling as they focus on the technical aspects of producing sounds in time and with some awareness of the changing chords. ${ }^{9}$ As those students continue to improvise, they may find that they can manipulate sound in ways that allow them and their peers to experience a general becoming-feeling, perhaps becoming-sadness or becoming-joy. Reimer (2003) asserts that through processes such as clarifying, organizing, and refining, the “education of feeling” involves musical creation and listening that concentrate feelings and "rid” them of ideas that weaken rather than strengthen them (92-3). Likewise, I posit that over time students can practice making the kinds of subtle decisions - the placement of a silence or the inflection on a specific note - that allow for more nuanced experiences of becoming-feeling.

This refining of becoming-feeling need not necessitate formal education; students can develop such skills through their own exploration and through informal learning outside of schools. Yet, Reimer (2003) explains that, just as English teachers can assist students in communicating via language, music educators can aid students in organizing and clarifying their expressive practices. Students can develop their own experiences of becoming-feeling by learning from teachers who, for instance, model certain rhythms and articulations or who explain how the judicious use of specific chord tones can create momentary grinding tensions and creative resolutions. 
Becoming-feeling, however, deviates from Reimer’s description because it acknowledges the impossibility of expressing feelings unambiguously. Offering an analogy between reading/writing and music making, Reimer (2003) asserts, "Reading the clarified thought another has written gives us clarified meaning to share” (91). If artistic practices involve forces that circulate and change, then while teachers and students can work to clarify their experiences of becoming-feeling, they cannot communicate singular “clarified meanings.” There might exist overarching agreement that a jazz solo belongs to the general category of "happy” or “angry,” but each individual's past experiences, current circumstances, and potential future trajectories make her experiences of becoming-feeling unique not only to that person but to that time and place.

Additionally, while Reimer (2003) asserts that clarifying and organizing feeling serves as a central purpose of music education, a synthesis of Langer's and Deleuze's work enables an alternative, equally if not more important role for music education in relation to feelings. Langer (1951) hints at the ways in which artistic experiences may complicate rather than clarify, asserting that artworks can offer one understandings of previously unknown feelings. She states, “Just as words can describe events we have not witnessed, places and things we have not seen, so music can present emotions and moods we have not felt, passions we did not know before” (222). In her later writing, she also briefly mentions that art can formulate "a new way of feeling” that can lead to societal changes $(1957,71)$. In other words, artistic experiences enable not just the refinement and deeper understanding of existing feelings but the opening up to new possibilities regarding what it means to feel.

Going further, Deleuze and Guattari (1994) explain, “A great novelist is above all an artist who invents unknown or unrecognized affects and brings them to light as the becoming of 
his characters” (174). For Deleuze, the value of artistic processes comes from embracing the foreign rather clarifying the known. Drawing on Delezue and Guattari’s writings about becoming-minoritarian, Elizabeth Gould (2007) summarizes, “We must experiment, play, dazzle, take risks, and be willing to fail, trusting ourselves as well as our students” (212).

As such, in addition to more refined and ordered understandings, musically educative experiences centered on becoming-feeling can lead to more complex and confused ones. Returning to the example of students improvising over the 12-bar blues, in tandem with exploring how they might clarify a certain becoming-feeling through their performing and listening over time, teachers and students might consider how they can foster divergent becoming-feeling experiences. How many different ways of becoming-feeling can a student express using the same notes or rhythms? How drastically or minimally can a becoming-feeling change over the course of a solo while still remaining interesting to the performer and listeners? How do diverse students become-feeling differently while listening to a single student’s improvisation? Building on Deleuze and Guattari’s (1994) assertion that the arts can foster an "I do not know that has become positive and creative” (128), teachers and students might embrace the vitality of disorder by seeking out and experimenting with previously unimagined experiences of becoming-feeling, perhaps both within the 12-bar blues and by hybridizing or completely reimagining the 12-bar blues. In such instances, the unknown becomes not a deficit in need refining and ordering but a place of possibility valuable in its own right.

Noting the potentialities of "becoming-musician," Gould (2012) challenges current music education practices that "specifically stereotype, limit, and exclude” (81). Expanding on such thinking, I post that these two potentially-overlapping ways of engaging with becoming-feeling moving towards refinement and embracing divergent potentialities - can inform not just the 
goals of single classes or units but the orientation of entire music education programs. Over the course of their music education, when do students have sustained opportunities to becomingfeeling in ways that assist them in clarifying and organizing their own expressivity? When do music educators engage students in learnings that enhance how they might use existing musical practices to share their becoming-feelings with others? When do music education programs confine teachers and students within current ideas of becoming-feeling, and when do they foster opportunities to engage with divergent becoming-feelings, including both through known musical practices and through previously unimagined ones? By experimenting with various "becoming-feelings,” teachers and students can broaden and deepen their understandings of themselves, others, and musical life as they currently exist as well as embrace an "I do not know” that fosters a feelingful "people to come.”

\section{References}

Alperson, P. 2004. 'The Philsoophy of Music: Formalism and Beyond.” In The Blackwell Guide to Aesthetics, edited by P. Kivy, 254-275. Malden, MA: Blackwell Publishing.

Ahlberg, L. 1994. “Susanne Langer on Representation and Emotion in Music.” British Journal of Aesthetics 34 (1): 69-80.

Bogue, R. 2003. Deleuze on Music, Painting, and the Arts. New York: Routledge.

Bowman, W. 1998. Philosophical Perspectives on Music. New York: Oxford University Press. Campbell, P.S., C. Connell, and A. Beegle. 2007. “Adolescents’ Expressed Meanings of Music in and out of School.” Journal of Research in Music Education 55 (3): 220-236. doi: $10.1177 / 002242940705500304$

Colebrook, C. 2002. Gilles Deleuze. New York: Routledge. 
Colebrook, C. 2005. “Actuality.” In The Deleuze Dictionary, edited by A. Parr, 9-11. Edinburgh: Edinburgh University Press.

Damasio, A.R. 1999. The Feeling of What Happens: Body and Emotion in the Making of Consciousness. Orlando, FL: Harcourt.

DeNora, T. 1999. “Music as a Technology of Self.” Poetics 27: 31-56. doi:10.1016/S0304$422 X(99) 00017-0$

Deleuze, G. (1990) 1995. Negotiations: 1972-1990. Translated and edited by M. Joughlin. New York: Columbia University Press.

Deleuze, G. and F. Guattari. (1980) 1987. A Thousand Plateaus: Capitalism and Schizophrenia. Translated and edited by B. Massumi. Minneapolis, MN: University of Minnesota Press.

Deleuze, G. and F. Guattari F. (1991) 1994. What is Philosophy? Translated by H. Tomlinson and G. Burchell. New York: Columbia University Press.

Elliott, D. J. 1995. Music Matters: A New Philosophy of Music Education. New York, NY: Oxford University Press.

Elliott, D. J. and M. Silverman. 2012. "Rethinking Philosophy, Re-viewing MusicalEmotional Experiences.” In The Oxford Handbook of Philosophy in Music Education, edited by W. Bowman \& A. Frega, 37-62. New York: Oxford University Press.

Elliott, D. J. and M. Silverman. 2015. Music Matters: A Philosophy of Music Education. 2nd ed. New York: Oxford University Press.

Grosz, E. 1995. Space, Time, and Perversion. New York: Routledge.

Grosz, E. 2008. Chaos, Territory, Art: Deleuze and the Framing of the Earth. New York: Columbia University Press. 
Gould, E. 2007. “Legible Bodies in Music Education: Becoming-Matter.” Action, Criticism, and Theory for Music Education 6 (4): 201-223.

Gould, E. 2012. “Uprooting Music Education Pedagogies and Curricula: Becoming Musician and the Deleuzian Refrain.” Discourse: Studies in the Cultural Politics of Education 33 (1): 75-86. doi:10.1080/01596306.2012.632168

Langer, S.K. 1951. Philosophy in a New Key. $2^{\text {nd }}$ ed. Cambridge, MA: Harvard University Press. Langer, S.K. 1953. Feeling and Form. New York: Charles Scribner’s Sons.

Langer, S.K. 1957. Problems of Art: Ten Philosophical Lectures. New York: Charles Scribner's Sons.

May, T. 2003. “When is a Deleuzian Becoming?” Continental Philosophy Review 36: 139153.

May, T. 2005. Gilles Deleuze: An Introduction. Cambridge, UK: Cambridge University Press. Oxford English Dictionary. 2000. Oxford: Oxford University Press.

Reimer, B.A. 1970. A Philosophy of Music Education: Advancing the Vision. Upper Saddle River, NJ: Prentice Hall.

Reimer, B.A. 1989. A Philosophy of Music Education: Advancing the Vision. $2^{\text {nd }}$ ed. Upper Saddle River, NJ: Prentice Hall.

Reimer, B.A. 2003. A Philosophy of Music Education: Advancing the Vision. $3^{\text {rd }}$ ed. Upper Saddle River, NJ: Prentice Hall.

State Education Agency Directors of Arts Education. 2014. "National Core Arts Standards: A conceptual framework for arts learning.” Retrieved from http://www. nationalartsstandards.org/content/conceptual-framework 
Villani, A. 2006. “Why am I Deleuzian?” In Deleuze and Philosophy, edited by C. Boundas, 227-249. Edinburgh, UK: Edinburgh University Press.

\section{Notes}

\footnotetext{
${ }^{1}$ Campbell, Connell, and Beegle (2007) write specifically about "emotions” rather than feelings. While related, a distinction between the two is articulated in the Synthesis section of this paper.

${ }^{2}$ Both Langer and Deleuze write primarily about "art" in terms of specific "artworks," thus reifying "art” and endowing specific "artworks" with stable identities. Such thinking is problematic because it does not fully attend to art as a process and it neglects how one's engagement with an "artwork" can evolve over time.

${ }^{3}$ Langer (1953) directly contrasts art with philosophy, writing, "Art is neither philosophy nor a substitute for philosophy, but is itself an epistemological datum about which we can philosophize” (118). Similarly, Deleuze and Guattari (1994) distinguish between philosophy, science, and art, arguing that they "think" through concepts, functions, and sensations, respectively (198). The philosopher creates concepts in order to offer consistency, the scientist creates functions that give the world points of reference, and the artist composes sensations in order to "restore" the infinite (197).

${ }^{4}$ The problematic nature of this position is addressed in the "Limitations" section of this essay.

${ }^{5}$ It is important to note that Langer writes solely about Western classical music. It follows from her writing that while other forms of music making, such as popular music, may portray the forms of feeling unambiguously, they do not necessarily do so in ways that foster processes such as contemplation and understanding as Langer describes them.

${ }^{6}$ What constitutes societal "advancement" is a contentious topic about which Langer offers no further clarity.

${ }^{7}$ I attend to "artistic experiences" rather than "aesthetic experiences." The term "aesthetic" implies a "critique of taste" (Oxford English Dictionary 2000) and has historically functioned to relegate certain musical practices. While the term "artistic experiences" subsumes "aesthetic experiences," by avoiding the propagation of a preordained artistic hierarchy, it resists the potentially problematic connotations of the latter.

${ }^{8}$ Feelings and even emotions more broadly play only a minimal role in contemporary music education rhetoric. For example, the extensive 2014 National Core Music Standards make only two references to emotions, in standards MU:Pr5.1.7 and MU:Pr5.1.8, and one reference to "feelings" in association with ideas and concepts (State Education Agency Directors of Arts Education 2014). Likewise, the advocacy portion of the National Association for Music Education's website (http://www.nafme.org/take-action/what-to-know/) makes little mention of feelings or emotions.

${ }^{9}$ In using this example, I am not arguing that technical considerations necessarily precede or inhibit becomingfeeling.
} 